\title{
A RANDOMIZED CLINICAL TRIAL ON IMIPRAMINE AND OXYBUTYNIN FOR THE TREATMENT OF CHILDREN WITH PRIMARY NOCTURNAL ENURESIS
}

\author{
SUDIP DAS GUPTA ${ }^{1}$, MD. RASIDUZZAMAN ${ }^{2}$, MD. ZAHURUL HAQUE ${ }^{3}$, YESMIN SULTANA $^{4}$, \\ MOHAMMAD MAHFUZUR RAHMAN 5
}

\begin{abstract}
Background: Nocturnal enuresis is a common childhood problem. There are several treatment options for the treatment of children with primary enuresis including behavioral modification, drug therapy like tricyclic antidepressant, vasopressin analog and anticholinergic drugs.

Objective: To observe the efficacy of oxybutynin and imipramine for the treatment of children with primary nocturnal enuresis in terms of symptom relief and disease control.

Materials and methods: A randomized clinical trial was conducted in urology outpatient department, Sir Salimullah Medical College Mitford Hospital, Dhaka from May 2015 to April 2016. Total 70 patients with primary nocturnal enuresis were selected according to selection criteria. After duly taking informed written consent, patients were randomly divided into 2 groups by lottery method. In this way 35 patients were selected as group$A$ and 35 patients were selected as group-B. Patients of group-A were treated with imipramine and Group- $B$ were treated with oxybutynin.

Results: Age range of the subjects was from 5-16 years. Among them $30 \%$ of the subjects in the imipramine group were between $7-9$ years of age and $30 \%$ of the subjects in the oxybutynin group were between 5-7 years of age. The male-female ratio was 1.2:1. Thirty five percent of the subjects had positive family history while remaining $65 \%$ did not have such history. At the base line study, $80 \%$ of the subjects did not show satisfactory result following 2 weeks of behavioral modification while 20\% showed improvement. Before starting drug therapy, 60\% patients had 4-5 bed-wetting nights/week. Following treatment, frequency of bed wetting dropped sharply to $<3$ at the end of month 3 and begin to rise again after discontinuation of therapy. At the end of month 3, imipramine cured in $46.7 \%$ cases with adverse effects like insomnia, nausea, anxiety, palpitation, lethargy while oxybutynin cured $40 \%$ patients with more adverse effects like headache, palpitation, dry mouth, constipation, tiredness, nervousness and fever. Early relapse of nocturnal enuresis 3 months after withdrawal the drugs and it was higher in the imipramine treated group than oxybutynin treated group which was $47.8 \%$ and $45 \%$ respectively.
\end{abstract}

Conclusion: Outcome of imipramine is better than oxybutynin and side effects are significantly higher in oxybutynin. Imipramine is more useful for the treatment of children with primary nocturnal enuresis.

Key Words: Nocturnal enuresis, imipramine, oxybutynin, urodynamic study.

Bangladesh J. Urol. 2018; 21(2): 76-82

1. Associate Professor and Head, Department of Urology, Sir Salimullah Medical College Mitford Hospital,

2. MS Urology Final Part Student, SSMC, Dhaka

3. MS Urology Final Part Student, SSMC, Dhaka

4. $\mathrm{HMO}, \mathrm{SSMCH}$, Dhaka

5. Assistant Registrar, Urology, SSMCMH, Dhaka

Correspondences: Dr. Sudip Das Gupta, Associate Professor and Head, Dept. of Urology, Sir Salimullah Medical College Mitford Hospital Received: 9 August 2017

\section{Intoduction}

Nocturnal enuresis or bed wetting is defined as the persistence of spontaneous and inappropriate voiding of urine during sleep after the age of expected bladder control [1]. It is a common childhood problem which affects $15-20 \%$ of 5 year old children, $5 \%$ of 10 year old children, $7 \%$ of 7 year olds, $2-3 \%$ of $12-14$ year 
olds, and $1-2 \%$ of people aged 15 years and over [2]. Various factors contribute to the development of nocturnal enuresis, most notably genetic factors and stressful early life events. Physiologic disturbances such as nocturnal polyuria, small functional bladder capacity and decreased arousal response to the full bladder have also been identified [3].

The International Children's Continence Society has recommended the following standardization of terminology: nocturnal enuresis is the involuntary loss of urine that occurs only at night. It is normal voiding that happens at an inappropriate and socially unacceptable time and place [4].

It is either primary when the child has never been dry, or secondary enuresis when the child has relapsed after initial night time dryness. The male to female ratio for nocturnal enuresis is three to two [5]. It occurs more in children with positive family history $(77 \%$ if both parents and $43 \%$ if single parent had the condition [6].

Children are not considered enuretic until they have reached five years of age. Mentally disabled children should have reached a mental age of four years before they are considered enuretic. For the diagnosis of nocturnal enuresis to be established, a child five to six years old should have two or more bed-wetting episodes per month, a child older than six years of age should have one or more wetting, episodes per month [7].

Most children have achieved normal bladder control by the age of 2 to 3 years. Girls are earlier than boys. At age 6 year $10 \%$ have enuresis. Most children spontaneously gain bladder control by 10 years. Approximately $10 \%$ spontaneous resolution occurs per year [8].

But even at the age of 14 year, $5 \%$ still have enuresis, which may bring social and emotional stigma, stress and inconvenience to both child with enuresis and their families. Children who wet bed may experience parental disapproval, sibling teasing and repeated treatment failure that may lower self-esteem. From 15 to 25 percent of bed-wetters have secondary enuresis but the treatment approach and anticipated response are the same [4].

Nocturnal enuresis is a non-fatal problem and has a good prognosis. For those families who ask for help, some will meet physician who share the traditional view on enuresis as a marginal problem, requiring little attention and no treatment. But it is not true for at least $5 \%$ of children with nocturnal enuresis who will remain enuretic for the rest of their lives. Nocturnal enuresis is a very significant handicap for the affected child. Nocturnal enuresis is still perceived as a shameful condition and kept as a secret. But there is nothing shameful about bed wetting [9]. In case of primary nocturnal enuresis there is no organic lesion present that means it is functional. The causes of Primary nocturnal enuresis is multifactorial such as- (a) Delayed functional maturation of central nervous system causing failure of arousal (b) Genetic/familial (c) Sleep disorderdeep sleep (d) Behavior and psychological disorder (e) Hormonal-low level of night time ADH secretion in children with primary nocturnal enuresis causes urine over production.

A carefully obtained history, physical examination and urinalysis are sufficient for evaluation of most children in order to exclude any underlying pathology (developmental, neurological, obstructive sleep apnea or organic urinary tract diseases) that might present with enuresis [10].Treatment is not recommended before the age of 5 years because at this age only $15 \%$ of children are still bed-wetting and most urinary incontinence fades away naturally [11].

\section{Treatment includes:}

1-Nonspecific measures such as decrease fluid intake at night, awakening the child during night and avoiding food and drink.

2-Drug therapy which includes: tricyclic antidepressant (Imipramine), vasopressin analog (desmopressin) and anticholinergic drugs (Oxybutynin, Tolterodine).

3-Behavioural modification: recent studies, even in a limited number of cases, suggest the efficacy of behavioral therapy for enuresis [12].

Imipramine is a tricyclic antidepressant which has been used from long ago. It has anticholinergic activity, alters the sleep and arousal mechanism and increases nocturnal $A D H$ production. It can cure enuresis in about $40 \%$ to $50 \%$ cases and results in improvement in another $10 \%$ to $20 \%$. Discontinuation of the medication causes relapse in up to $60 \%$ of patients. It has some side effects such as anxiety, insomnia, dry mouth, nervousness, tremor, blurred vision, constipation, tachycardia, sweating, drowsiness, postural hypotension, confusion, tinnitus, headache, allergic skin reactions, raised intraocular pressure etc. 
Oxybutynin is an anticholinergic and antispasmodic agent that decreases uninhibited bladder contractions. It competitively antagonizes the M1, M2 and M3 subtypes of the muscarinic acetylcholine receptor. It also has direct spasmolytic effects on bladder smooth muscle as a calcium antagonist. Oxybutynin is used successfully for treatment of urologic disorders such as urge incontinence and neurogenic bladder. Because detrusor hyperactivity plays a part in nocturnal enuresis, oxybutynin is suggested to be effective when treating nocturnal enuresis. It has some side effects including dry mouth, difficulty in urination, constipation, blurred vision, drowsiness and dizziness [13].

\section{Methods:}

A randomized clinical trial was conducted in urology outpatient department, Sir Salimullah Medical College Mitford Hospital, Dhaka from May 2015 to April 2016. Total 70 cases were selected according to selection criteria from the patients attending Urology outpatient department of SSMCMH with history suggestive of primary nocturnal enuresis. After duly taking written informed consent, patients were randomly divided into 2 groups (Group-A and Group-B) by lottery method. In this way 35 patients were selected as group-A and 35 patients were selected as group-B. Cases of group-A were treated with single dose of imipramine $25 \mathrm{mg}$ half an hour before bed time and Group-B were treated with oxybutynin tablet $5 \mathrm{mg}$ twice daily.

\section{Results and Observations:}

Total 70 cases were selected randomly according to the selection criteria from the patients attending urology outpatient department of SSMC Mitford Hospital, Dhaka with primary nocturnal enuresis. Of them 10 patients (5 patients in each group) were lost to follow up.So, they were excluded leaving 30 patients in each group, total 60 for final analysis. At the end of 3 months of treatment, outcome and side-effects of drugs were measured. After 3 months in group-A imipramine was tapered for next 2 week, then the drug was stopped. In group-B oxybutynin was stopped after 3 months of treatment. Outcome was again measured in terms of frequency of bed-wettings per week and compared between groups.

Table II shows that $30 \%$ of the subjects in the imipramine group was 7-9 years of age, followed by $23.3 \%$ between $9-11$ years, $20.0 \%$ between $5-7$ years, $16.7 \%$ between $11-13$ and $10 \%$ above 13 years. In the Oxybutynin group, $30 \%$ of the subjects were between $5-7$ years of age, $23.4 \%$ between $7-9$ years, $20 \%$ of the subjects between $9-11$ years, $13.3 \%$ between $11-13$ years and another $13.3 \%$ above 13 years of age. No significant difference was observed between the mean ages of imipramine $(9.7 \pm 2.4)$ and oxybutynin $(9.1 \pm$ 2.8) group $(p=0.270)$ (Table II). The age ranges of subjects in the imipramine and oxybutynin group were $6-15$ years and $5-16$ years respectively.

Table I

Comparison between two groups according to age distribution $(n=60)$

\begin{tabular}{|c|c|c|c|c|c|c|c|}
\hline \multirow[t]{2}{*}{ Age in years } & \multicolumn{2}{|c|}{ Imipramine group $(n=30)$} & \multicolumn{2}{|c|}{ Oxybutynin group $(n=30)$} & \multicolumn{2}{|c|}{ Total $(n=60)$} & \multirow[t]{2}{*}{$p$ value } \\
\hline & Number & $\%$ & Number & $\%$ & Number & $\%$ & \\
\hline$\overline{5-7}$ & 6 & 20.0 & 9 & 30.0 & 15 & 25.0 & \\
\hline $7-9$ & 9 & 30.0 & 7 & 23.4 & 16 & 26.7 & \\
\hline $9-11$ & 7 & 23.3 & 6 & 20.0 & 13 & 21.6 & \\
\hline $11-13$ & 5 & 16.7 & 4 & 13.3 & 9 & 15.0 & \\
\hline$>13$ & 3 & 10.0 & 4 & 13.3 & 7 & 11.7 & \\
\hline Mean $\pm S D$ & \multicolumn{2}{|c|}{$9.7 \pm 2.4$} & \multicolumn{2}{|c|}{$9.1 \pm 2.8$} & \multicolumn{2}{|c|}{$11.1 \pm 3.1$} & $0.27^{\mathrm{ns}}$ \\
\hline Range (min - max) & \multicolumn{2}{|c|}{$(6-15)$} & \multicolumn{2}{|c|}{$(5-16)$} & \multicolumn{2}{|c|}{$(5-16)$} & \\
\hline
\end{tabular}

$n s=$ Not significant $(p>0.05), P$ value reached from unpaired $t$-test

Table II

Distribution of patients by bed wetting at baseline $(n=60)$

\begin{tabular}{lcc}
\hline No. of bed wetting (nights/week) & Number & Percentage (\%) \\
\hline $2-3$ & 12 & 20.0 \\
$4-5$ & 36 & 60.0 \\
$6-7$ & 12 & 20.0 \\
\hline
\end{tabular}


Table IV describes that $60 \%$ of the subjects had an average of $4-5$ enuretic nights per week, 20\% 2-3 nights per week and $20 \%$ had 6 - 7 nights per week.

Table $\mathrm{V}$ demonstrates that mean number of wetting/ week at baseline and at the end of month 3 were almost same in both imipramine and oxybutynin groups $(4.20 \pm 1.24$ vs. $4.37 \pm 1.25, p=0.60$ and $2.17 \pm 1.18$ vs. $2.37 \pm 1.38, p=0.54$ respectively). The mean frequency of bed- wetting/week 3 months after discontinuation of drugs, although, was higher in the imipramine group compared to the oxybutynin group, the difference did not turn to be significant ( $p$ $=0.27$

Table VI presents the side effects of drugs during treatment. The side effects like Dry mouth, headache, hesitancy and constipation were significantly higher in oxybutynin group ( $p=0.01,0.005,0.001$ and 0.02$)$, where as insomnia $(p=0.001)$ and nausea $(p=0.02)$ demonstrated its significant presence in the imipramine group $(p=0.005)$. Tiredness and nervousness were completely absent in imipramine group compared to $13.3 \%$ in oxybutynin group $(p=0.05)$. No other side effects were statistically significant $(p>0.05)$.

Table III

Comparison of bed wetting between two groups $(n=60)$

\begin{tabular}{lccc}
\hline Number of bed wetting & $\begin{array}{c}\text { Imipramine group } \\
(\mathrm{n}=30)\end{array}$ & $\begin{array}{c}\text { Oxybutynin group } \\
(\mathrm{n}=30)\end{array}$ & $\begin{array}{c}\mathrm{P} \\
\text { Mean } \pm \text { SD }\end{array}$
\end{tabular}

$n s=$ Not significant $(p>0.05), P$ value reached from unpaired $t$-test

Table IV

Comparisons of side effects of drugs between two study groups $(n=60)$

\begin{tabular}{|c|c|c|c|c|c|}
\hline \multirow[t]{2}{*}{ Age in years } & \multicolumn{2}{|c|}{ Imipramine group $(n=30)$} & \multicolumn{2}{|c|}{ Oxybutynin group $(n=30)$} & \multirow[t]{2}{*}{$\mathrm{p}$ value } \\
\hline & Number & $\%$ & Number & $\%$ & \\
\hline Dry mouth & 3 & 10.0 & 9 & 30.0 & $0.01^{\mathrm{s}}$ \\
\hline Anxiety & 4 & 13.3 & 3 & 10.0 & $0.50^{\mathrm{ns}}$ \\
\hline Insomnia & 6 & 20.0 & 00 & 00.0 & $0.001^{\mathrm{s}}$ \\
\hline Nausea & 5 & 16.7 & 00 & 00.0 & $0.02^{\mathrm{s}}$ \\
\hline Tiredness & 0 & 00.0 & 4 & 13.3 & $0.05^{\mathrm{ns}}$ \\
\hline Nervousness & 0 & 00.0 & 4 & 13.3 & $0.05^{\mathrm{ns}}$ \\
\hline Palpitation & 3 & 10.0 & 2 & 6.7 & $0.21^{\mathrm{ns}}$ \\
\hline Constipation & 00 & 00.0 & 5 & $16 . .7$ & $0.02^{s}$ \\
\hline Hesitancy & 00 & 00.0 & 6 & 20.0 & $0.001^{\mathrm{s}}$ \\
\hline Headache & 00 & 00.0 & 7 & 23.3 & $0.005^{s}$ \\
\hline Fever & 00 & 00.0 & 1 & 3.3 & 0.500 \\
\hline Lethargy & 1 & 3.3 & 00 & 00.0 & 0.500 \\
\hline
\end{tabular}

$s=$ Significant $(p<0.05) ; n s=$ Not significant

$P$ value reached from Pearson's Chi-square test and Fisher's Exact test. 
Sudip Das Gupta et al

Table V

Outcome of imipramine at the end of the month 3 $(n=30)$

\begin{tabular}{lccc}
\hline $\begin{array}{l}\text { Age in } \\
\text { years }\end{array}$ & $\begin{array}{c}\text { Cured } \\
(\geq 90 \% \text { dry } \\
\text { night/week })\end{array}$ & $\begin{array}{c}\text { Improved } \\
(50-90 \% \text { dry } \\
\text { night/week })\end{array}$ & $\begin{array}{c}\text { Failed } \\
(<50 \% \text { dry } \\
\text { night/week }) \\
\mathrm{n}(\%)\end{array}$ \\
\hline $5-7$ & $3(10 \%)$ & $2(6.7 \%$ & $1(3.3 \%)$ \\
$7-9$ & $3(10 \%)$ & $3(10 \%)$ & $1(3.3 \%)$ \\
$9-11$ & $2(6.7 \%)$ & $1(3.3 \%)$ & $0(0.0 \%)$ \\
$11-13$ & $1(3.3 \%)$ & $2(6.7 \%)$ & $2(6.7 \%)$ \\
$>13$ & $5(16.7 \%)$ & $1(3.3 \%)$ & $3(10.0 \%)$ \\
\hline Total & $14(46.7 \%)$ & $9(30 \%)$ & $7(23.3 \%)$ \\
\hline
\end{tabular}

Outcome of imipramine at the end of the month 3 shows $14(46.7 \%)$ of the subjects cured $(\geq 90 \%$ of the dry nights/ week), 9 (30\%) improved (50\%-90\% of dry nights/week) and in $7(23.3 \%)$ treatment was failed $(<50 \%$ of dry night/week).

Outcome of oxybutynin at the end of the month 3 shows $12(40 \%)$ of the subjects exhibited cure (e" $90 \%$ of the dry nights/week), 8 (26.7\%) improved (50\%-90\% of dry nights/week) and in rest $10(33.3 \%)$ cases treatment was considered to be failed ( $<50 \%$ of dry night/week).

\section{Table VI}

Outcome of Oxybutynin at the end of the month 3 $(n=30)$

\begin{tabular}{lccc}
\hline $\begin{array}{l}\text { Age in } \\
\text { years }\end{array}$ & $\begin{array}{c}\text { Cured } \\
(\geq 90 \% \text { dry } \\
\text { night/week })\end{array}$ & $\begin{array}{c}\text { Improved } \\
(50-90 \% \text { dry } \\
\text { night/week })\end{array}$ & $\begin{array}{c}\text { Failed } \\
(<50 \% \text { dry } \\
\text { night/week }) \\
\mathrm{n}(\%)\end{array}$ \\
\hline $5-7$ & $2(6.7 \%)$ & $1(3.3 \%)$ & $6(20 \%)$ \\
$7-9$ & $4(13.3 \%)$ & $2(6.7 \%)$ & $1(3.3 \%)$ \\
$9-11$ & $2(6.7 \%)$ & $1(3.3 \%)$ & $1(3.3 \%)$ \\
$11-13$ & $2(6.7 \%)$ & $2(6.7 \%)$ & $0(0.0 \%)$ \\
$>13$ & $2(6.7 \%)$ & $2(6.7 \%)$ & $2(6.7 \%)$ \\
\hline Total & $12(40 \%)$ & $8(26.7 \%)$ & $10(33.3 \%)$ \\
\hline
\end{tabular}

Table IX shows the early relapse of nocturnal enuresis in all groups were assessed by follow up the subjects 3 months after withdrawal of the drugs and it was higher in the imipramine treated group than oxybutynin treated group which was $47.8 \%$ and $45 \%$ respectively with statistically insignificant difference $(p=0.69)$.
Table VII

Relapse of nocturnal enuresis after finishing the course of treatment

\begin{tabular}{lccc}
\hline $\begin{array}{l}\text { Age in } \\
\text { years }\end{array}$ & $\begin{array}{c}\text { Imipramine } \\
\mathrm{n}(\%)\end{array}$ & $\begin{array}{c}\text { Oxybutynin } \\
\mathrm{n}(\%)\end{array}$ & $\begin{array}{c}\mathrm{P} \\
\text { value }\end{array}$ \\
\hline $5-7$ & $4(17.4 \%)$ & $3(15 \%)$ & $0.69^{\text {ns }}$ \\
$7-9$ & $2(8.7 \%)$ & $2(10 \%)$ & \\
$9-11$ & $2(8.7 \%)$ & $2(10 \%)$ & \\
$11-13$ & $1(4.3 \%)$ & $1(5 \%)$ & \\
$>13$ & $2(8.7 \%)$ & $1(5 \%)$ & \\
\hline Total & $11(47.8 \%)$ & $9(45 \%)$ & \\
\hline
\end{tabular}

ns $=$ Not significant $(p>0.05)$

$P$ value reached from Fisher's Exact test.

\section{Discussion}

This study was carried out in Sir Salimullah medical College Mitford Hospital from May 2015 to April 2016. All cases were selected from outpatient department of urology, SSMCMH. A total of 70 subjects were initially selected for study. Of them 10 patients were lost to follow up leaving 60 for final analysis. In this study imipramine $25 \mathrm{mg}$ tablet half an hour before bed time and oxybutynin $5 \mathrm{mg}$ tablet twice daily were used in $>5$ year patients in two separate groups for 3 months. Then the efficacy and adverse effects were noted after 3 months from a voiding diary which the parents or patients were asked to maintain. After 3 months in group-A imipramine was tapered for next 2 week, then the drug was stopped. In group-B oxybutynin was stopped after 3 months of treatment. Outcome was again measured in terms of frequency of bed-wettings per week and compared between groups.

The primary objective of the drug treatment of primary nocturnal enuresis is to control bed-wetting and thereby reducing the sufferings of the parents and children. In this study the number of wetting night per week, adverse effects of the drugs and relapse rate were used as variables to assess the effectiveness and safety of the drugs.

Initially all the patients were observed for two weeks without any drug but with behavioral modification such as time voiding, fluid restriction at evening and bladder control exercise and their baseline enuretic frequency observed in term of bed wetting night per week. By behavioral modification majority $(80 \%)$ of the subjects did not show satisfactory result following 2 weeks while $20 \%$ showed improvement to some extent . In another 
study, it was found that 6 month observation along with fluid restriction \& time voiding only $16 \%$ became continent [14].

In this study, $30 \%$ of the subjects in the imipramine group were $7-9$ years of age, followed by $23.3 \%$ between $9-11$ years, $20.0 \%$ between $5-7$ years, $16.7 \%$ between $11-13$ and $10 \%$ above 13 years. In the oxybutynin group, $30 \%$ of the subjects were between $5-7$ years of age, $23.4 \%$ between $7-9$ years, $20 \%$ of the subjects between $9-11$ years, $13.3 \%$ between 11 13 years and another $13.3 \%$ above 13 years of age. No significant difference was observed between the mean ages of imipramine $(9.7 \pm 2.4)$ and oxybutynin $(9.1 \pm 2.8)$ group $(p=0.27)$. The age ranges of subjects in the imipramine and oxybutynin group were 6-15 years and 5-16 years respectively (Table I). It is near similar to the age group in a separate study treating with imipramine group which was 5-8 years (26.6\%), 8-12 years $(60 \%)$ and above 12 years $(13.3 \%)$ while in oxybutynin group was 5-8 years (33.3\%), 8-12 years $(46.6 \%)$ and above 12 years (20\%) [6].

There is a significant gender distribution in nocturnal enuresis where the male to female ratio is three to two [5]. In this study, among 60 patients $55 \%$ were male, $45 \%$ were female and the ratio was $1.2: 1$ which is almost similar to the reported ratios in the fore mentioned studies.

Heredity plays a significant contributing factor in the etiology of nocturnal enuresis [11], which was also obvious in this study where $35 \%$ of enuretics had a positive family history and another $65 \%$ it had none.

Before starting drug therapy, $60 \%$ patients have $4-5$ bed-wetting night/week, $20 \%$ have 2-3 bed-wetting nights/week and $20 \%$ have 6-7 bed-wetting night/week (Table II). In imipramine group, before starting drug the mean enuretic frequency was $4.20 \pm 1.24 \mathrm{SD}$ and in oxybutynin group it was $4.37 \pm 1.25 \mathrm{SD}$. The difference was not significant.

After 3 months of drug treatment these mean enuretic frequency dropped to $2.17 \pm 1.18 \mathrm{SD}$ in imipramine group and $2.37 \pm 1.38 \mathrm{SD}$ in oxybutynin group (bed wetting night/week). This improvement is not statistically significant.

After 3 months of discontinuation of the drugs again these mean values rises to $2.60 \pm 1.43 \mathrm{SD}$ in imipramine and $2.50 \pm 1.20 \mathrm{SD}$ ) in oxybutynin group (Table III). This finding is almost similar with another study, which shown that imiprainine causes significant improvement of nocturnal enuresis but withdrawl causes relapse in significant number of patients [14].

In this study, standard definitions determined by the International children's continence society were adopted to designate final treatment outcomes on medication as - cured- $>90 \%$ reduction in wetting episodes, improved - $>50 \%$ reduction or failed $-<50 \%$ reduction [15].

At the end of 3 months drug treatment it was found that in the imipramine group cured in $46.7 \%$, improved in $30 \%$ and failed in $23.3 \%$ (Table $\mathrm{V}$ ). This result is consistent with

another study where cure rate was $53.3 \%$, improved $26.6 \%$ and $20 \%$ failed to treatment at the end of month 3 with imipramine on medication [6].

On the other hand, at the end of 3 months treatment $40 \%$ of the oxybutynin group exhibited cure, $26.7 \%$ improved and in rest $33.3 \%$ cases treatment was considered to be failed (Table $\mathrm{VI}$ ). This result is almost consistent in a randomized double-blind controlled trial [16] where the response rate of oxybutynin was $45 \%$.

In the oxybutynin group dry mouth $(30.0 \%)$, headache (23.3\%), hesitancy $(20.0 \%)$ and constipation (16.7\%) were significantly higher. Insomnia (20.0\%) and nausea $(16.7 \%)$ were higher in imipramine group. Tiredness and nervousness were absent in imipramine group compared to $13.3 \%$ in oxybutynin group. No other adverse effects were statistically significant (Table IV). This finding is consistent with another study with imipramine where sleep disturbance was $16.7 \%$ and constipation was $13.3 \%$ while in the oxybutynin, dry mouth was $36.6 \%$ and headache was $19.9 \%$ [6]. In another study of oxybutynin in children with primary nocturnal enuresis, mild side effects (fatigue, dizziness, headache, dry mouth) noted in 5 of the 30 children who completed the study [17].

In a study in children treated with primary nocturnal enuresis by imipramine adverse effects were anxiety, dry mouth, insomnia, nausea which is consistent with this study [18].

Early relapse of nocturnal enuresis in all age groups were assessed by follow up of the subjects 3 months after withdrawal of the drugs and it was higher in the imipramine treated group than oxybutynin treated group which was $47.8 \%$ and $45 \%$ respectively with statistically insignificant difference $p=0.69$ (Table VII). In another study, the oxybutynin group showed a clearly lower relapse rate $(31.8 \%)$ compared to the imipramine 
(63.2\%) group being approximately twice as much as of the oxybutynin group. However, the difference was not statistically significant $P=0.095$ [2].

This result correlates with the study where the rate of early relapse in imipramine group was $45.8 \%$ while that of oxybutynin treated group was $42.5 \%$ which is slightly lower than that of imipramine group but the response rate was higher in the later group ( $53.3 \%$ vs $33.3 \%)$ making imipramine a better option [6].

This result is also supported by several other studies where they found imipramine cured patients with primary enuresis during treatment period and after discontinuation of therapy it cause relapse in significant cases [19-21].

\section{Conclusion}

This study showed a potential role of imipramine and oxybutynin for the treatment of children with primary nocturnal enuresis. Outcome of imipramine is better than oxybutynin and side effects are significantly higher in oxybutynin.

Imipramine is more useful for the treatment of children with primary nocturnal enuresis.

\section{References:}

1. Lawless MR, McEderry DH. Nocturnal enuresis: current concepts.pediatr Rev.2001 ; (12):399-407. (Lawless MR et al, 2001).

2. Maryam Seyfhashemi,Raheb Ghorbani,Abbas Zolfaghari.Desmopressin, Imiprmine and Oxybutynin in the treatment of primary nocturnal enuresis:A randomized clinical trial; Iran Red Crescent Med J, 2015;17(7):e16174. (Maryam et al, 2015).

3. Kiddo DA .Nocturnal enuresis. Canada Medical Association Journal 2012;184(8):908-11. (Kiddo DA, 2012).

4. Thiedke C C: Nocturnal Enuresis.American Family physician 2003 67: 1499-1506.

5. Schmitt BD: Nocturnal enuresis. Pediatrics in Review. 1997; 18,183-191.

6. Maitham H.Kenber and Kussay M.Zwain :A Comparative Study Between Imipramine, Oxybutynin and Non Drug Therapy in Treating Nocturnal Enuresis, The Iraqi Postgraduate Medical Journal 2009, 8(2): 143-147.

7. Naseri M. Low Dose Oxybutynin in childhood nocturnal Enuresis .J Ped.Nephrology 2014; 2(2): 67-75.
8. Lyon $\mathrm{C}$ and Schnall $\mathrm{J}$ : What is best treatment for nocturnal enuresis in children? Journal of Family practice, 2005,93: 143-149 .

9. Hjalmas K: Enuresis in children. Brazilian Journal of Urology, 2002, 88: 232-249.

10. Stephen A, Kuff RJ: Voiding dysfunction in children. In Walsh p, Petik A Vaugham D Campbells Urology eighth edition 2002, 22732280.

11. Neveus T,Tuvemd T,Lackgren $G$ et al: Bladder capacity and renal concentrating ability in enuresis: Pathogenic implications. The Journal of Urology.2001, 165:2022-2025.

12. Pennesi M, Kussay $M Z$ Zwain: Behavioral therapy for primary nocturnal enuresis. The Journal of Urology, 2004; 171,408-410.

13. Mehta D (Ed.) 2006.British National Formulary 51. Pharmaceutical Press. ISBN 0-85369-668-3.

14. Monda JM and Husmann DA: Primary nocturnal enuresis : A comparison among observation, imipramine,Desmopressin acetate and bed wetting alarm system. The Journal of Urology, 1995; 154,745-748.

15. Munding $M$, Wessells $H$, Thornberry $B$ et al: Use of Tolterodine in childen with dysfunctional voiding :An initial report .The Journal of Urology, 2001; 165,926-928.

16. Montaldo $\mathrm{P}$,Tafuro L,Rea $\mathrm{M}$ et al.Desmopressin and Oxybutynin in monosymptomatic nocturnal enuresis: a randomized, double-blind, placebocontrolled trial and assessment of predictive factors.BJU International 2012;110(8 pt B):3816.

17. Lovering JS, Tallett SE.Mckendry BI: Oxybutynin efficacy in the treatment of primary enuresis. Pediatrics 1988;82(1):104-6.

18. Mark SD and Frank JD: Nocturnal enuresis. British Journal of Urology. 1995; 75, 427-434.

19. MacLean REG: Imipramine hydrochloride (Tofranil) and enuresis. Amer J Psychiatry. 1960; 117,551 .

20. Kunin SA, Limbert DJ, Platzker ACG et al: The efficacy of imipramine in the management of enuresis. J Urol. 1970; 104, 612.

21. Martin G I: Imipramine pamoate in the treatment of childhood enuresis: a double-blind study. Amer J Dis Child. 1971; 122, 42. 